\title{
Building Block Candidates for the Design of Proton Exchange Membranes: Maleimide and
}

\section{Its Homologues}

\section{Xuejiao $\mathrm{Li}^{1}$, Liuming Yan $^{2 *}$, Baohua Yue ${ }^{2 *}$}

${ }^{1}$ Department of Physics, ${ }^{2}$ Department of Chemistry, Shanghai University, 99 Shangda Road, Shanghai 200444, China

\begin{abstract}
Density functional theory (DFT) calculations are applied to the study of proton transport in maleimide and its homologues, succinimide and phthalimide. The calculations reproduce correctly their structural characteristics and reveal the hydrogen bonding and proton hopping properties. Specifically, the calculations show that the potential barrier for proton transfer between two maleimide molecules is about $30.60 \mathrm{kcal} \cdot \mathrm{mol}^{-1}$ mediated by one or two water molecules with correction of solvation effect by water, and will decrease to about 13.22 $\mathrm{kcal}^{\mathrm{m}} \mathrm{mol}^{-1}$ if ethylphosphonic acid molecule is used as mediator with correction of solvation effect by phosphoric acid. In addition, the calculations also show that succinimide and phthalimide possess similar characteristics compared to maleimide. Finally, it is concluded that maleimide and its homologues are building block candidates for the design of high-temperature proton exchange membranes.
\end{abstract}

Keywords: proton exchange membrane; maleimide; succinimide; proton transport; density functional theory

\footnotetext{
* Corresponding author. Tel.: 8621-66132405, fax: 8621-66132405. E-mail: liuming.yan@t.shu.edu.cn (L.Y.) yueyue902@163.com (B.Y.)
} 


\section{Introduction}

High-temperature proton exchange membrane fuel cells (HT-PEMFCs) have been paid more and more attention as energy conversion devices because of higher energy conversion efficiency, noiseless operation and low pollution emission, especially the humidity-independent performances, enhanced electrocatalytic activity, and improved tolerance to impurities in fed-gas. ${ }^{1}$ Nevertheless, the large scale commercialization of HT-PEMFCs depends heavily on the high-temperature performances of the proton exchange membranes (PEMs). ${ }^{2}$ Though perfluorosulfonic acid polymers (PFSA) have achieved great progress in proton conductivity, chemical and electrochemical stability, the application of PFSA in PEMFCs is limited to temperatures that liquid water exists. At high temperature, the liquid water which hydrates the PFSA evaporates and the proton conductivity of PFSA degrades. Therefore, the development of novel proton conducting materials possessing high proton conductivity at high temperature and dehydrated or even anhydrous states is of the utmost importance.

Researches on PEMs are being conducted through experimental and theoretical efforts toward better performance at high temperature. ${ }^{3}$ For example, the proton conductivity and mechanical property can be improved by doping with inorganic compounds as water adsorption or retention materials, ${ }^{4-5}$ or by addition of organophosphates and azoles or amides to substitute water as hydration solvent. ${ }^{6-8}$ Studies have shown that membranes functionalized by phosphonic acid groups possess much better proton conductivity under dehydrated or even anhydrous states attributing to the self-dissociation and amphoteric character of the phosphonic acid group. ${ }^{9}$ The complex H-bonding network between phosphonic acid groups tethered to the polymer backbones result in the ability to conduct proton transport via the Grotthuss mechanism at high-temperature and low-humidity conditions. ${ }^{10-11}$ During past years, great efforts have 
been devoted to the synthesis of phosphonic acid functionalized polystyrene, poly(ether sulfone), polyimides and so on. ${ }^{12-15}$

Maleimide (MI) is also an interesting amphoteric molecule, with a dissociation constant $\mathrm{p} K_{a}=5.57$ evaluated from conductivity measurement (provided as figure $\mathbf{S} 1$ in the supporting information). Actually, the H-bonding donor and acceptor of a MI molecule is similar to those of triazole molecules, both 1,2,3-triazole and 1,2,4-triazole, which are widely accepted as building blocks in the design of proton conducting materials at high temperature under a water deficient environment. ${ }^{16-17}$ As being shown in triazole, the tautomerization is an important characteristic for the proton transfer in hydrophilic compounds, which promotes long-range network structures for facile proton transfer. ${ }^{18}$ MI also shows abundant tautomerization pathways, especially with the mediation of other hydrophilic compounds, like organophosphates. ${ }^{15}$ In this aspect, Kalia et al. studied both the gas phase and water-assisted tautomerization of MI based on density functional theory, ${ }^{19}$ and Li et al. studied the proton transport in solid state MI using ab initio molecular dynamics simulations. ${ }^{20}$ Based on these considerations, we propose that MI and its homologues, such as succinimide (SI) and phthalimide (PI), are building block candidates for the design of high-temperature proton conducting materials.

Density functional theory (DFT) calculations are widely applied to the study of proton transport in the field of proton exchange membrane. For example, Kreuer et al. applied DFT calculations to the study of sulfonic acid, phosphonic acid, and imidazole functionalized heptane in terms of bond rotational barrier of the functional groups and intermolecular H-bonding, and concluded that the imidazole is most labile when tethered to an alkyl chain and the energy penalty for proton transfer is greatest for imidazole and least for phosphonic acid. ${ }^{21}$ Yue et al. 
studied the proton transfer pathways between ethylphosphonic acid (EPA) and 1,2,3-triazole using DFT calculations and concluded that the existence of EPA will greatly reduce the tautomerization activation energy of triazole. ${ }^{22}$ Zhou et al. developed a phosphotungstic acid functionalized and mesoporous silica-based high conductivity PEM, and revealed that the proton transfer involves both inter- and intra-molecular proton transfer pathways and evaluated the activation energy based on DFT calculations. $^{23}$ Inter- and intra-molecular H-bonding and proton transport in a series of acid-base complexes including different acid groups and nitrogenous heterocyclic rings were also studied by DFT calculations. ${ }^{24-25}$

In this work, DFT calculations will be applied to the characterization of proton transport in MI and its homologues, SI and PI, in terms of transition states and proton hopping. First, we will describe the DFT method in next section. And then, we will optimize the density functional and basis set in section 3.1, and will compare the intermolecular H-bonding energies in section 3.2. Third, we will study the transition states and energy barriers of proton transport mediated by water or EPA molecules as ethylene phosphonic acid is the most occurred repeat unit in PEMs. In addition, we also measured the overall conductivity of composites of MI and methyl phosphonic acid (MPA, the simplest organic phosphonic acid) at various compositions using electrochemical impedance spectroscopy (EIS). Finally, we will summarize the important results and propose that the MI and its homologues are building block candidates for the design of proton conducting polymers.

\section{Methods}

\subsection{Calculation method}

The generalized gradient approximation (GGA) functionals and hybrid functionals are 
widely accepted in quantum chemistry because these functionals can provide reasonably accurate predictions for geometries and thermodynamics of small covalent molecules. ${ }^{26-28}$ However, the dispersion and $\mathrm{H}$-bonding interactions are insufficiently represented by these functionals. In order to evaluate adequately the dispersion and H-bonding interactions, more accurate functionals, such as the meta-GGA functionals (the M06 family), dispersion corrected functionals (the B97-D), and long-range corrected functionals (the CAM-B3LYP), are developed. ${ }^{29-31}$ Among the many physical and chemical processes, the proton transport is such a typical process which is greatly related to the weak intermolecular interactions, especially the H-bonding interaction. In order to evaluate their applicability to the proton transport in MI and its homologues, three functionals, including the hybrid B3LYP functional, the meta-GGA M06-2X functional and the counterpoise-corrected $\omega$ B97X-D functional, are compared in terms of intermolecular H-bonding interaction based on the MP2 reference. For these three functionals, the B3LYP is widely accepted for the calculation of organic molecules and considered being able to provide chemistry accuracy. The M06-2X and $\omega$ B97X-D functionals contain empirical dispersion corrections, especially suitable for the modeling of structures and energies of H-bonding interaction. ${ }^{30}$ In addition, suitable basis set is selected from five basis sets including 6-311G(d), 6-311+G(d), 6-311+G(d,p), 6-311+G(2d,p), and 6-311++G(2d,2p). Based on the optimized functional and basis set, proton transport in molecular systems composed of MI, SI, PI, water, and EPA is studied in terms of geometric optimizations, frequency calculations, and transition state locations. Besides, the basis set superposition error (BSSE) are evaluated using counterpoise correction for energetics related to both intermolecular H-bonding and activation of proton transfer. The solvent effect is evaluated based on polarizable continuum model (PCM) using, respectively, water and phosphoric acid as solvents. The static 
dielectric constant of phosphoric acid is assumed to be 18.90 by extrapolation of experimental dielectric constant of phosphoric acid solution as shown in figure $\mathbf{S 3}$ in the supporting information. ${ }^{32}$ The optimized geometries are confirmed to be local minima without imaginary frequencies, or to be transition states with only one imaginary frequency. In addition, the reaction paths are traced by the internal reaction coordination (IRC) to ensure the correctness of the transition states. All the above calculations are conducted using the Gaussian 09 suite of programs. $^{33}$

\subsection{Experimental method}

The conductivities of the MI-based composites containing different amounts of MPA (Heowns Biochem Technologies Co. Ltd.) are characterized using electrochemical impedance spectroscopy (EIS). Firstly, the MI powders and MPA powders are mixed, ground, and pressed into round slabs $(\phi=12.0 \mathrm{~mm}, t \approx 0.520 \mathrm{~mm})$ under a pressure of $14.0 \mathrm{Mpa}$. And then, the slabs are conditioned in a temperature and humidity controlled chamber (Boleda, model GDS-50) for 12 hours before each EIS measurement. Third, the EIS measurements are conducted using a multichannel potentiostat (Solartron, SI 1287) and a frequency response analyzer (Solartron, 1255B) by pressing the slabs between two round Pt electrodes. EIS are recorded in a frequency range from $1 \mathrm{~Hz}$ to $1 \mathrm{MHz}$ with perturbation of $10.0 \mathrm{mV}$. The overall resistances of the slabs are obtained from the intercepts of the impedance spectra with the real axis at high frequencies, and the conductivities are evaluated from the overall resistances.

\section{Results and discussion}

\subsection{Density functionals and basis sets optimization}

The density functionals and basis sets are optimized according to the intermolecular 
H-bonding interaction between two MI molecules as shown in table 1. The H-bonding energy is evaluated using three functionals including B3LYP, M06-2X, and $\omega$ B97X-D in combination with five basis sets of $6-311 \mathrm{G}(\mathrm{d}), \quad 6-311+\mathrm{G}(\mathrm{d}), \quad 6-311+\mathrm{G}(\mathrm{d}, \mathrm{p}), \quad 6-311+\mathrm{G}(2 \mathrm{~d}, \mathrm{p})$, and 6-311++G(2d,2p) (be detailed in table S1 of supporting information).

Table 1 Uncorrected and BSSE corrected H-bonding energies between two MI molecules evaluated using three functionals in combination with five basis sets, the values in parentheses are MP2 H-bonding energies evaluated using the corresponding DFT geometries (unit: $\mathrm{kcal} \cdot \mathrm{mol}^{-1}$ )

\begin{tabular}{|c|c|c|c|c|c|c|}
\hline Basis set & B3LYP & $\mathrm{B} 3 \mathrm{LYP}_{\mathrm{BSSE}}$ & M06-2X & M06-2X $\mathrm{X}_{\mathrm{BSSE}}$ & $\omega \mathrm{B} 97 \mathrm{X}-\mathrm{D}$ & $\omega \mathrm{B} 97 \mathrm{X}-\mathrm{D}_{\mathrm{BSSE}}$ \\
\hline $6-311 \mathrm{G}(\mathrm{d})$ & $\begin{array}{c}12.09 \\
(12.62)\end{array}$ & $\begin{array}{l}9.65 \\
(9.07)\end{array}$ & $\begin{array}{c}13.03 \\
(12.49)\end{array}$ & $\begin{array}{l}10.99 \\
(8.95)\end{array}$ & $\begin{array}{c}13.78 \\
(12.56)\end{array}$ & $\begin{array}{l}11.64 \\
(8.87)\end{array}$ \\
\hline $6-311+G(d)$ & $\begin{array}{c}10.31 \\
(12.04)\end{array}$ & $\begin{array}{r}9.68 \\
(9.47)\end{array}$ & $\begin{array}{c}11.86 \\
(11.87)\end{array}$ & $\begin{array}{l}11.13 \\
(9.34)\end{array}$ & $\begin{array}{c}12.39 \\
(12.02)\end{array}$ & $\begin{array}{l}11.62 \\
(9.28)\end{array}$ \\
\hline $6-311+G(d, p)$ & $\begin{array}{c}10.36 \\
(12.01)\end{array}$ & $\begin{array}{c}9.74 \\
(9.43)\end{array}$ & $\begin{array}{c}11.82 \\
(11.84)\end{array}$ & $\begin{array}{l}11.10 \\
(9.34)\end{array}$ & $\begin{array}{c}12.58 \\
(12.02)\end{array}$ & $\begin{array}{l}11.83 \\
(9.27)\end{array}$ \\
\hline $6-311+G(2 d, p)$ & $\begin{array}{c}10.05 \\
(12.41)\end{array}$ & $\begin{array}{c}9.61 \\
(10.41)\end{array}$ & $\begin{array}{c}11.22 \\
(12.37)\end{array}$ & $\begin{array}{c}10.73 \\
(10.39)\end{array}$ & $\begin{array}{c}12.33 \\
(12.45)\end{array}$ & $\begin{array}{c}11.79 \\
(10.34)\end{array}$ \\
\hline $6-311++G(2 d, 2 p)$ & $\begin{array}{c}10.04 \\
(12.84)\end{array}$ & $\begin{array}{c}9.60 \\
(10.56)\end{array}$ & $\begin{array}{c}11.30 \\
(12.82)\end{array}$ & $\begin{array}{c}10.81 \\
(10.55)\end{array}$ & $\begin{array}{c}12.33 \\
(12.93)\end{array}$ & $\begin{array}{c}11.81 \\
(10.50)\end{array}$ \\
\hline
\end{tabular}

The H-bonding energy evaluated using B3LYP functional decreases with the size of basis sets from 12.09 to $10.04 \mathrm{kcal} \cdot \mathrm{mol}^{-1}$. Meanwhile the H-bonding energy calculated at MP2 level of theory and the corresponding geometries fluctuates between 12.01 and $12.84 \mathrm{kcal} \cdot \mathrm{mol}^{-1}$, with 
a variation of $0.83 \mathrm{kcal} \cdot \mathrm{mol}^{-1}$. And the average difference between the B3LYP functional and MP2 theory is about $-1.81 \mathrm{kcal} \cdot \mathrm{mol}^{-1}$. That is to say, the H-bonding energy does not converge between the B3LYP functional and MP2 theory. For the M06-2X functional, the H-bonding energy converges to about $11.25 \mathrm{kcal} \cdot \mathrm{mol}^{-1}$ as the basis set size increases, and the H-bonding energy evaluated using the MP2 theory increases from 11.84 to $12.82 \mathrm{kcal} \cdot \mathrm{mol}^{-1}$ (the $6-311 \mathrm{G}(\mathrm{d})$ basis set is an outlier). In addition, the difference between the M06-2X functional and MP2 theory does not converge with a minimum difference of $-0.01 \mathrm{kcal} \cdot \mathrm{mol}^{-1}$ and a maximum difference of $-1.52 \mathrm{kcal} \cdot \mathrm{mol}^{-1}$. For the $\omega \mathrm{B} 97 \mathrm{X}-\mathrm{D}$ functional, the H-bonding energy fluctuates between 12.33 to $13.78 \mathrm{kcal} \cdot \mathrm{mol}^{-1}$, and converges at about $12.40 \mathrm{kcal} \cdot \mathrm{mol}^{-1}$ as the basis set size increases, and the corresponding MP2 H-bonding energy fluctuates between 12.02 and 12.93 $\mathrm{kcal} \cdot \mathrm{mol}^{-1}$. The average difference between $\omega \mathrm{B} 97 \mathrm{X}-\mathrm{D}$ functional and MP2 theory is only 0.29 $\mathrm{kcal} \cdot \mathrm{mol}^{-1}$.

After BSSE correction, all the H-bonding energies between two MI molecules are slightly decreased; however, their order does not change. As expected, the BSSE is more pronounced for small basis sets, which do not provide satisfactory description for wave functions farther from the nucleus, especially for the non-bonded interactions. Therefore, it could be concluded that the $\omega \mathrm{B} 97 \mathrm{X}-\mathrm{D}$ functional provides the best H-bonding energy with the reference of MP2 theory, and the density functional theory always provides less H-bonding energy compared with the MP2 theory. Based on these calculations, the $\omega \mathrm{B} 97 \mathrm{X}-\mathrm{D}$ functional will be applied to the following calculations in combination with the $6-311+\mathrm{G}(2 \mathrm{~d}, \mathrm{p})$ basis set.

Figure 1 summarizes the optimized structure of intermolecular H-bonding between two MI

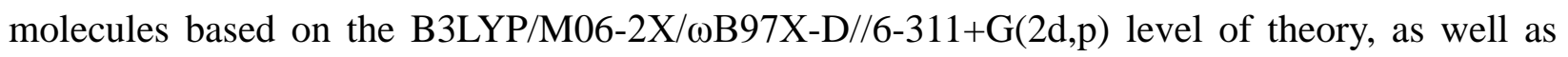
experimental values from crystal MI. ${ }^{34}$ For the $\mathrm{N}-\mathrm{H} \cdots \mathrm{O}$ bonding, the experimental distance 
varies from 2.851 to $2.917 \AA$, and the theoretical value is from 2.880 to $2.919 \AA$, with the $\omega \mathrm{B} 97 \mathrm{X}-\mathrm{D} / / 6-311+\mathrm{G}(2 \mathrm{~d}, \mathrm{p})$ in closest to the experimental values and the M06-2X//6-311+G(2d,p) the furthest. This is consistent with the fact that the $\omega B 97 \mathrm{X}-\mathrm{D} / / 6-311+\mathrm{G}(2 \mathrm{~d}, \mathrm{p})$ provides the strongest $\mathrm{H}$-bonding interaction. For the $\mathrm{C}=\mathrm{O}$ bond distances, the experimental values are in range of 1.190 to $1.221 \AA$, and the calculated values are between 1.197 to $1.204 \AA$, also in consistent with experimental values.

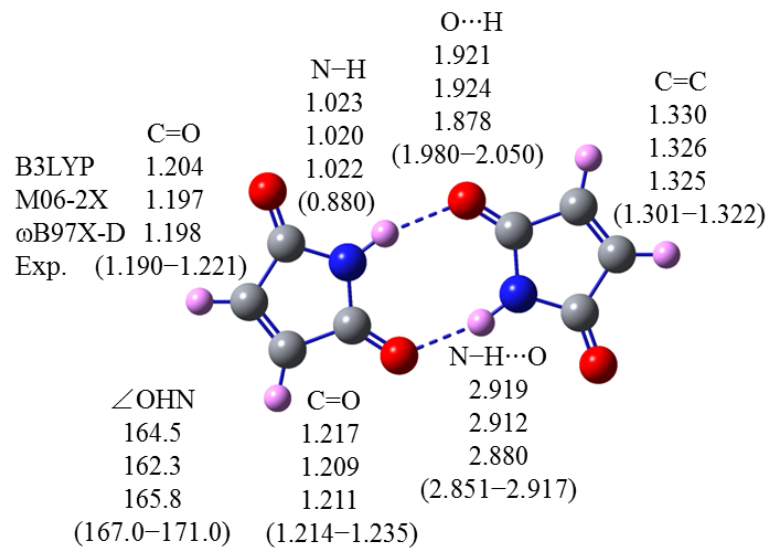

Fig. 1 Bond distances $(\AA)$ and angles (degree) between two MI molecules optimized using the B3LYP, M06-2X, and $\omega$ B97X-D functionals and 6-311+G(2d,p) basis set (color code: grey C, red $\mathrm{O}$, cyan $\mathrm{N}$, and purple $\mathrm{H})$.

\subsection{H-bonding energies of MI and its homologues}

Though the imidic nitrogen $(>\mathrm{N}-\mathrm{H})$ is only bonded to three atoms leaving two nonbonding lone pair electrons, the imidic nitrogen could only behave as proton donor because it accepts a planar $\mathrm{sp}^{2}$ hybridization attributing to the conjugation effect with two acyl $(\mathrm{C}=\mathrm{O})$ and one $\mathrm{C}=\mathrm{C}$ double bonds. The imidic nitrogen is more difficult to be protonated (low basicity) than the amine nitrogen. On the other hand, the acyl oxygen could act as proton acceptor in H-bonding, 
and thus, MI is an amphoteric compound. The proton affinity energies for acyl oxygen are $-198.32,-203.69$, and $-206.37 \mathrm{kcal} \cdot \mathrm{mol}^{-1}$ for the MI, SI, and PI, respectively, evaluated at theory level of $\omega \mathrm{B} 97 \mathrm{X}-\mathrm{D} / 6-311+\mathrm{G}(2 \mathrm{~d}, \mathrm{p})$ as summarized in table $\mathbf{S} 2$ in the supporting information. Therefore, the acyl oxygen atoms of MI show weaker proton affinity than those of SI and PI.
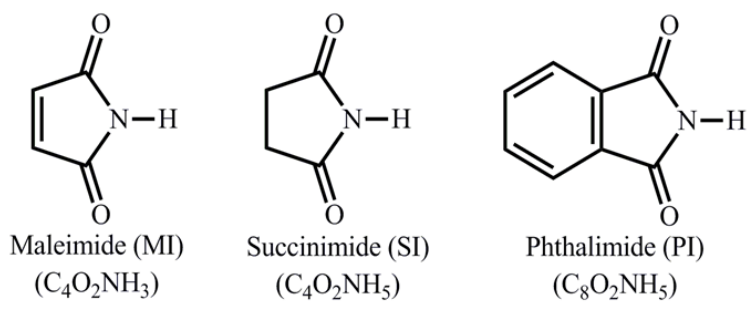

(a)

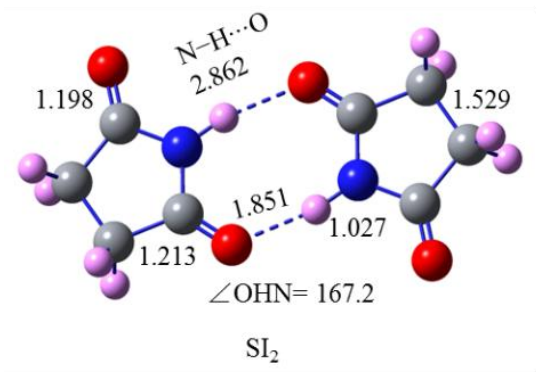

(b)

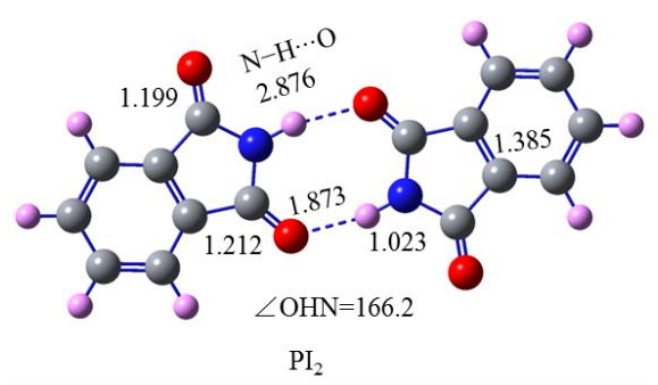

(c)

Fig. 2 (a) Maleimide MI and its homologues SI and PI; H-bonding between (b) two SI and (c) two PI molecules. 
In this study, we also compare the H-bonding energies of MI with its homologues, SI and $\mathrm{PI}$ in which the $\mathrm{C}=\mathrm{C}$ double bond is substituted, respectively, by a $\mathrm{C}-\mathrm{C}$ single bond and a conjugated $\mathrm{C}=\mathrm{C}$ double bond in a benzene ring as shown in figure $\mathbf{2 a}$. The acidic dissociation constant $\left(K_{a}\right)$ is a quantitative measure of the strength of an acid, and is related to the ionization degree of the acid in solution and thus the proton conductivity. ${ }^{35}$ The logarithmic acidic dissociation constants $\left(\mathrm{p} K_{a}\right)$ of imidic protons $(>\mathrm{N}-\mathrm{H})$ of $\mathrm{MI}, \mathrm{PI}$, and SI are 5.57 (measured in this work as shown in figure $\mathbf{S 1}$ of the supporting information), 9.90, and 9.62, respectively, with the imidic proton of MI the easiest to dissociate. ${ }^{36}$ From the BSSE corrected intermolecular $\mathrm{H}$-bonding energies as summarized in table 2 (uncorrected $\mathrm{H}$-bonding energies are detailed in table S3 provided in the supporting information), it could be seen that these three homologues possess similar intermolecular $\mathrm{H}$-bonding energies with the $\mathrm{SI}_{2}$ at $12.59 \mathrm{kcal} \cdot \mathrm{mol}^{-1}$ slightly greater than $\mathrm{PI}_{2}$ at $12.10 \mathrm{kcal} \cdot \mathrm{mol}^{-1}$ and $\mathrm{MI}_{2}$ at $11.79 \mathrm{kcal} \cdot \mathrm{mol}^{-1}$, and the $\mathrm{MI}_{2}$ the smallest. The $\mathrm{N}-\mathrm{H} \cdots \mathrm{O}$ distances are $2.880,2.862$, and $2.876 \AA$, respectively, for $\mathrm{MI}_{2}, \mathrm{SI}_{2}$, and $\mathrm{PI}_{2}$, also indicating the strongest $\mathrm{H}$-bonding interaction in $\mathrm{SI}_{2}$, the weakest in $\mathrm{MI}_{2}$, and the intermediate in $\mathrm{PI}_{2}$.

Table 2 H-bonding energies $-\Delta E\left(\mathrm{kcal} \cdot \mathrm{mol}^{-1}\right)$ after BSSE correction and $\mathrm{N}-\mathrm{H} \cdots \mathrm{O}$ distances $d$ ( $\mathrm{A})$ in $\mathrm{MI}_{2}, \mathrm{SI}_{2}$, and $\mathrm{PI}_{2}$ evaluated using $\omega \mathrm{B} 97 \mathrm{X}-\mathrm{D}$ functional in combination with five basis sets

\begin{tabular}{lcccccc}
\hline Basis set & $-\Delta E_{\mathrm{MI}}$ & $-\Delta E_{\mathrm{SI}}$ & $-\Delta E_{\mathrm{PI}}$ & $d_{\mathrm{MI}}$ & $d_{\mathrm{SI}}$ & $d_{\mathrm{PI}}$ \\
\hline 6-311G(d) & 11.64 & 12.30 & 11.91 & 2.893 & 2.881 & 2.892 \\
6-311+G(d) & 11.62 & 12.32 & 11.90 & 2.899 & 2.886 & 2.896 \\
$6-311+\mathrm{G}(\mathrm{d}, \mathrm{p})$ & 11.83 & 12.61 & 12.12 & 2.885 & 2.870 & 2.881 \\
$6-311+\mathrm{G}(2 \mathrm{~d}, \mathrm{p})$ & 11.79 & 12.59 & 12.10 & 2.880 & 2.862 & 2.876
\end{tabular}


The single-well potential or double-well potential with small barrier is an important characteristic of the intermediate complex for proton transfer in H-bonding. Figure $\mathbf{S 2}$ shows the potential energy surfaces of proton transfer in $\mathrm{MI}_{2}, \mathrm{SI}_{2}$, and $\mathrm{PI}_{2}$ systems. From figure $\mathbf{S 2}$, the distances of H-bonding which are susceptible to proton transfer processes are 2.341 2.391 for $\mathrm{MI}_{2}, 2.345 \sim 2.395 \AA$ for $\mathrm{SI}_{2}$, and 2.384 2.434 $\AA$ for $\mathrm{PI}_{2}$. The activation energies of proton transfer are from 0.00 to $1.91 \mathrm{kcal} \cdot \mathrm{mol}^{-1}$ for $\mathrm{MI}_{2}, 0.12$ to $3.70 \mathrm{kcal} \cdot \mathrm{mol}^{-1}$ for $\mathrm{SI}_{2}, 0.03$ to 3.09 $\mathrm{kcal} \cdot \mathrm{mol}^{-1}$ for $\mathrm{PI}_{2}$, agreeing with the above $\mathrm{H}$-bonding interaction energies.

\subsection{Water mediated proton transfer between two MI molecules}

In $\mathrm{H}$-bonding, $\mathrm{MI}$ donates its imidic proton and accepts proton via acyl $\mathrm{C}=\mathrm{O}$, and resulting tautomerization interconversion between the keto and the enol forms and easing the fast proton transfer. For example, Kalia et al. calculated that the energy barrier for intramolecular tautomerization of MI is $56.97 \mathrm{kcal} \cdot \mathrm{mol}^{-1}$ in gaseous phase, and decreases to $23.52 \mathrm{kcal} \cdot \mathrm{mol}^{-1}$ mediated by one water molecule at B3LYP/6-31+G(d) level of theory. ${ }^{19}$ In solid state, two neighboring MI molecules are bound together via intermolecular $\mathrm{N}-\mathrm{H} \cdots \mathrm{O} \mathrm{H}$-bonding and the imidic proton can hop between these two molecules. Such proton hopping process can be accelerated by water molecules or other amphoteric molecules existing between two MI molecules. In this section, we are going to evaluate the energy barriers of water mediated proton transfer in terms of intermolecular tautomerization. 

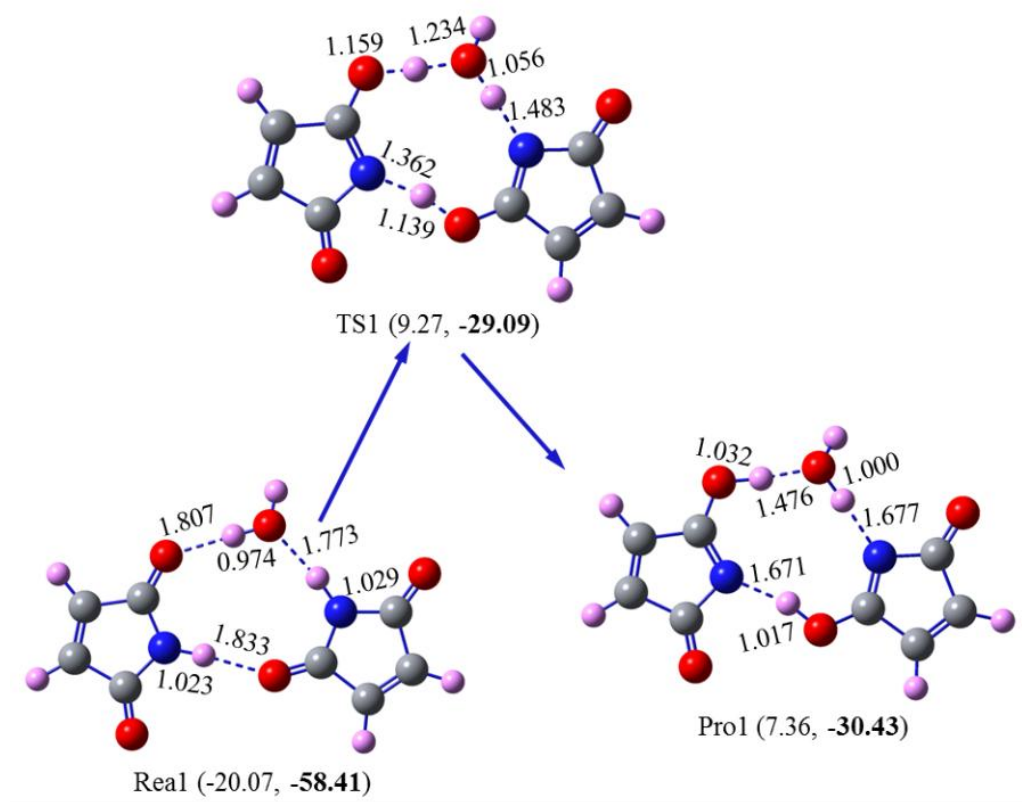

(a)

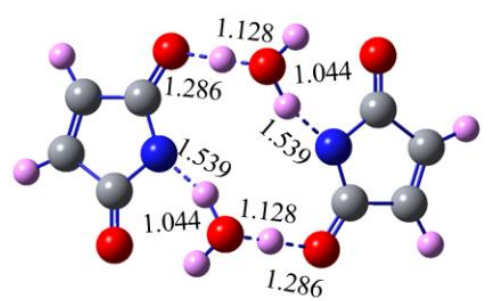

TS2 $(0.88,-46.49)$

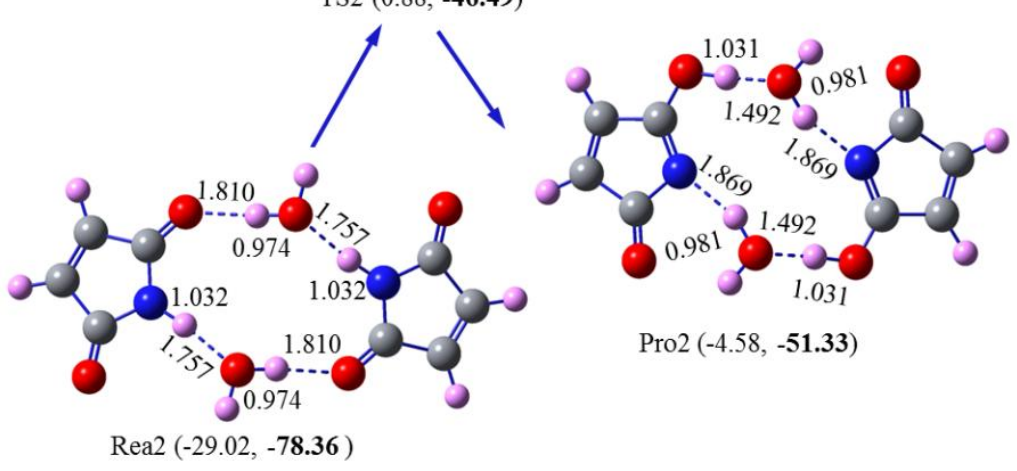

(b)

Fig. 3 Tautomerization of MI mediated by (a) one, and (b) two water molecules, the unbolded numbers in parentheses are energies relative to the isolated molecules in gaseous phase and the bolded numbers are corresponding energies with solvation correction (color code: grey $\mathrm{C}$, red $\mathrm{O}$, 
cyan $\mathrm{N}$, and purple $\mathrm{H})$.

In figure 3, it shows the water mediated proton transfer between two MI molecules including the initial states or reactants (Rea), transition states (TS), and products (Pro), as well as their energies relative to the isolated molecules in gaseous phase. For system $\mathrm{MI}_{2}-\mathrm{H}_{2} \mathrm{O}$ (figure 3a), the water molecule mediates the proton transfer from imidic group (Rea1) to acyl group (Pro1) via a transition state TS1. In Rea1, the protons are bonded to imidic nitrogen atoms in either MI molecules with $\mathrm{N}-\mathrm{H}$ distances at 1.023 and $1.029 \AA$, and $\mathrm{O} \cdots \mathrm{H}$ distances at 1.807 and $1.833 \AA$, respectively. In the TS1, the $\mathrm{N}-\mathrm{H}$ distances are elongated to 1.362 and $1.483 \AA$, and the $\mathrm{O}-\mathrm{H}$ distances are shortened to 1.139 and $1.159 \AA$. Finally in Pro1, both protons are transferred forming two lactim tautomers with $\mathrm{O}-\mathrm{H}$ distances at 1.017 and $1.032 \AA$. All the intermolecular H-bonding distances are summarized in table 3. And solvation corrections are evaluated using of PCM solvation model of water based on the same geometries optimized at $\omega B 97 X-D / 6-311+G(2 d, p)$ level of theory. Energetically, Rea1 possesses a binding energy of $-20.07 \mathrm{kcal} \cdot \mathrm{mol}^{-1}$ and the TS1 of $9.27 \mathrm{kcal} \cdot \mathrm{mol}^{-1}$, which decreases to $-58.41 \mathrm{kcal} \cdot \mathrm{mol}^{-1}$ and $-29.09 \mathrm{kcal} \cdot \mathrm{mol}^{-1}$ after PCM solvation correction, respectively. Despite of the significance of PCM solvation correction to the total energies, the activation energy of water mediated proton transfer, the energy difference between TS1 and Rea1, is unaffected with values at 29.34 $\mathrm{kcal} \cdot \mathrm{mol}^{-1}$ or $29.32 \mathrm{kcal} \cdot \mathrm{mol}^{-1}$ without or with solvation correction.

Table 3 Intermolecular H-bonding distances $d(\AA)$ in water and EPA mediated MI, SI, and PI systems evaluated at $\omega \mathrm{B} 97 \mathrm{X}-\mathrm{D} / 6-311+\mathrm{G}(2 \mathrm{~d}, \mathrm{p})$ level of theory 


\begin{tabular}{|c|c|c|c|c|c|c|}
\hline & $d_{\mathrm{N}-\mathrm{H} \cdots \mathrm{O}}$ & $d_{\mathrm{O}-\mathrm{H} \cdots \mathrm{O}}$ & $d_{\mathrm{N}-\mathrm{H} \cdots \mathrm{O}}$ & $d_{\mathrm{O}-\mathrm{H} \cdots \mathrm{O}}$ & $d_{\mathrm{N}-\mathrm{H} \cdots \mathrm{O}}$ & $d_{\mathrm{O}-\mathrm{H} \cdots \mathrm{O}}$ \\
\hline \multirow{2}{*}{$\mathrm{MI}_{2}-\mathrm{H}_{2} \mathrm{O}$} & 2.847 & 2.781 & 2.482 & 2.391 & 2.665 & 2.504 \\
\hline & 2.794 & & 2.538 & & 2.675 & \\
\hline \multirow{2}{*}{$\mathrm{MI}_{2}-2 \mathrm{H}_{2} \mathrm{O}$} & 2.772, & 2.783 & 2.539 & 2.413 & 2.774, & 2.523, \\
\hline & 2.772 & 2.783 & 2.539 & 2.413 & 2.774 & 2.523 \\
\hline MI-EPA & 2.759 & 2.672 & 2.479 & 2.406 & 2.636 & 2.508 \\
\hline \multirow{2}{*}{$\mathrm{MI}_{2}-\mathrm{EPA}$} & 2.743 & 2.735 & 2.554 & 2.392 & 2.663 & 2.463 \\
\hline & & 2.738 & & 2.688 & & 2.712 \\
\hline \multirow{2}{*}{$\mathrm{SI}_{2}-\mathrm{H}_{2} \mathrm{O}$} & 2.839 & 2.755 & 2.475 & 2.387 & 2.727 & 2.524 \\
\hline & 2.787 & & 2.524 & & 2.690 & \\
\hline \multirow{2}{*}{$\mathrm{SI}_{2}-2 \mathrm{H}_{2} \mathrm{O}$} & 2.746 & 2.788 & 2.506 & 2.444 & 2.817 & 2.537 \\
\hline & 2.746 & 2.788 & 2.506 & 2.444 & 2.817 & 2.537 \\
\hline SI-EPA & 2.761 & 2.650 & 2.475 & 2.412 & 2.656 & 2.529 \\
\hline \multirow{2}{*}{$\mathrm{SI}_{2}-\mathrm{EPA}$} & 2.779 & 2.683, & 2.531 & 2.392, & 2.701 & 2.486 \\
\hline & & 2.723 & & 2.652 & & 2.682 \\
\hline \multirow{2}{*}{$\mathrm{PI}_{2}-\mathrm{H}_{2} \mathrm{O}$} & 2.859, & 2.767 & 2.473 & 2.395 & 2.675 , & 2.511 \\
\hline & 2.793 & & 2.544 & & 2.681 & \\
\hline \multirow{2}{*}{$\mathrm{PI}_{2}-2 \mathrm{H}_{2} \mathrm{O}$} & 2.753, & 2.803, & 2.535 & 2.417 & 2.780 & 2.525 \\
\hline & 2.753 & 2.803 & 2.535 & 2.417 & 2.780 & 2.525 \\
\hline PI-EPA & 2.761 & 2.668 & 2.480 & 2.411 & 2.638 & 2.512 \\
\hline \multirow{2}{*}{$\mathrm{PI}_{2}-\mathrm{EPA}$} & 2.746 & 2.715 & 2.549 & 2.391, & 2.668 & 2.469 \\
\hline & & 2.760 & & 2.708 & & 2.731 \\
\hline
\end{tabular}


The system $\mathrm{MI}_{2}-2 \mathrm{H}_{2} \mathrm{O}$ (figure $3 \mathbf{b}$ ) shows the proton transfer between two MI molecules mediated by two water molecules. The bond lengths of $\mathrm{N}-\mathrm{H}$ and $\mathrm{O} \cdots \mathrm{H}$ in Rea2 are similar to that of Rea1, while for the TS2, one of the $\mathrm{N}-\mathrm{H}$ bond is elongated to $1.539 \AA$, and $\mathrm{O}-\mathrm{H}$ shortened to $1.286 \AA$. For the product Pro2, two of the imidic protons are transferred becoming two lactim protons, with $\mathrm{N} \cdots \mathrm{H}$ distances being elongated to $1.869 \AA$ and $\mathrm{O}-\mathrm{H}$ distances being shortened to $1.031 \AA$. The proton transfer barrier is $29.90 \mathrm{kcal} \cdot \mathrm{mol}^{-1}$ without PCM solvation correction, almost the same as that with one mediation water molecule, slightly different from those with PCM solvation correction (table 4).

Table 4 BSSE corrected energetics $\left(\mathrm{kcal} \cdot \mathrm{mol}^{-1}\right)$ related to the proton transfer in $\mathrm{MI}$ and the values in parentheses are corresponding energetics with PCM solvation correction ${ }^{\dagger}$

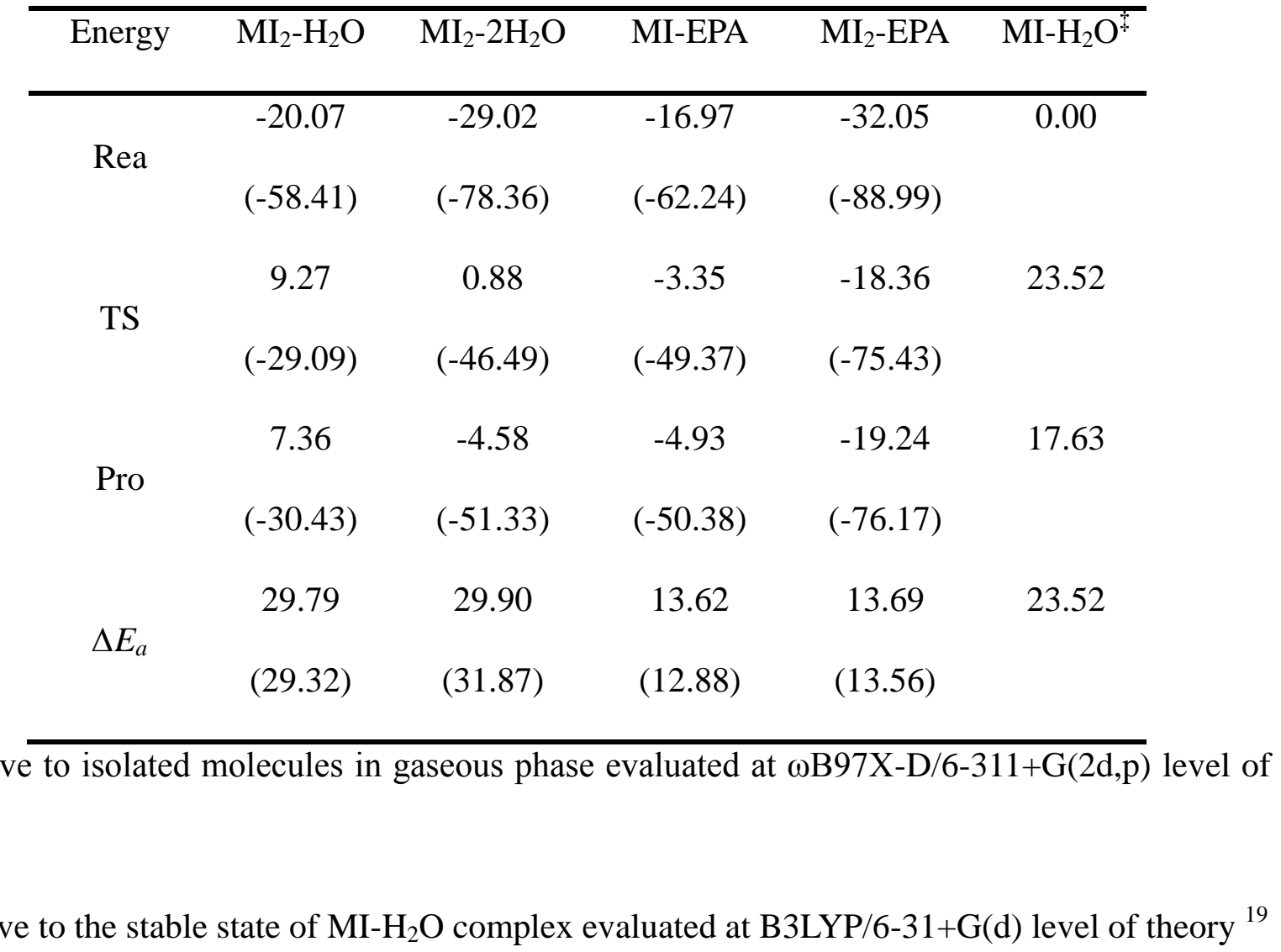




\subsection{EPA mediated proton transfer between two MI molecules}

From previous section, it is concluded that proton transfer occurs between two MI molecules mediated by water molecules because of the amphoteric characteristics of MI. In this section, we are going to study the EPA mediated proton transfer between two MI molecules since phosphonic acid is considered a potential substitution to the sulfonic acid based proton exchange membranes. And solvation corrections are evaluated using of PCM solvation model of phosphoric acid based on the same geometries optimized at $\omega$ B97X-D/6-311+G(2d,p) level of theory.

Table 4 reveals that solvation greatly lowers the total energies, however, the activation energies of proton transfer almost conserve. In figure 4, it shows the tautomerization of MI mediated by EPA molecule (molar ratio=1:1). In figure 4a, a MI molecule tautomerizes from a lactam structure to a lactim structure with an energy barrier of only $12.88 \mathrm{kcal} \cdot \mathrm{mol}^{-1}$ corrected with PCM solvation model in phosphoric acid, which is comparable to the experimental activation energy for phosphonic acid functionalized polyimide composite membranes. ${ }^{37}$ It is well known that the proton conductivity depends on the content of phosphonic acid. ${ }^{38}$ From figure $\mathbf{4 b}$ which shows the tautomerization in a system consisting of two MI molecules and one EPA molecule, it could be seen that an EPA could form triple fold H-bonding linkages between two MI molecules functioning simultaneously as H-bonding donor and acceptor. The proton transfer barrier between MI and EPA is $13.56 \mathrm{kcal} \cdot \mathrm{mol}^{-1}$, a little more than the energy barrier $12.88 \mathrm{kcal} \cdot \mathrm{mol}^{-1}$ and less than half of that between two MI molecules mediated by one or two water molecules. Therefore, it could be expected that MI will potentially improve the proton conductivity in EPA, and MI is a candidate solvation media for phosphonic acid based proton exchange membranes. 


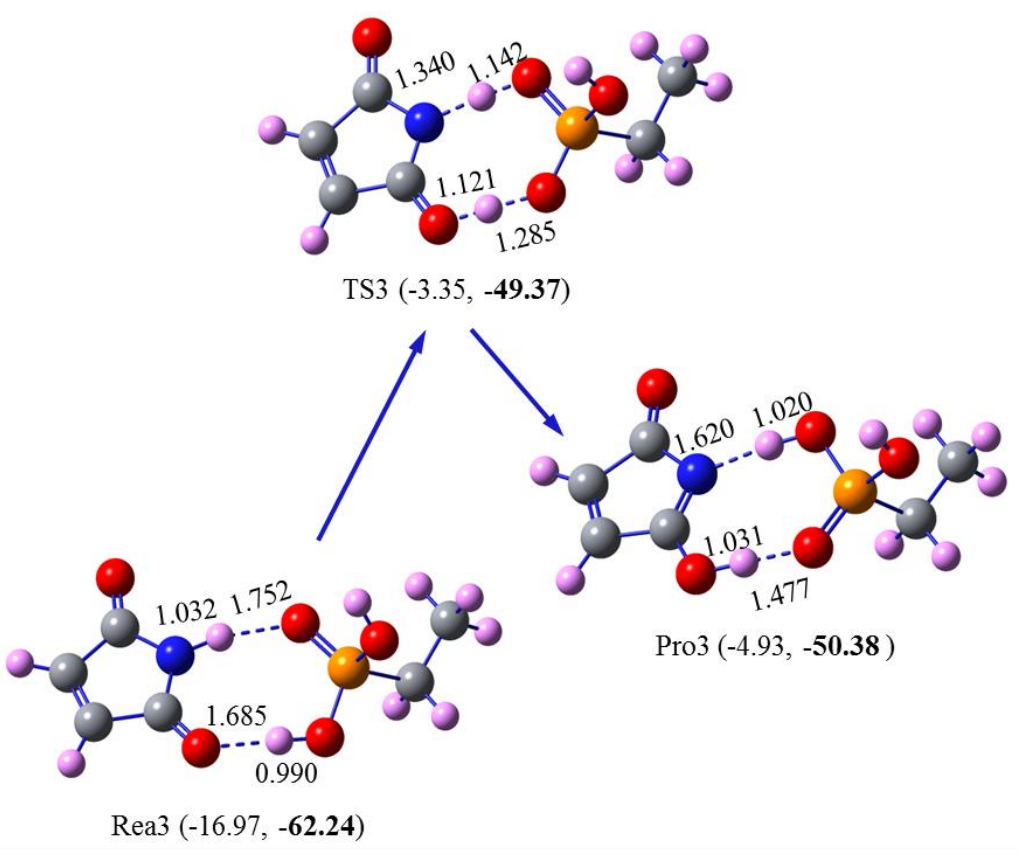

(a)

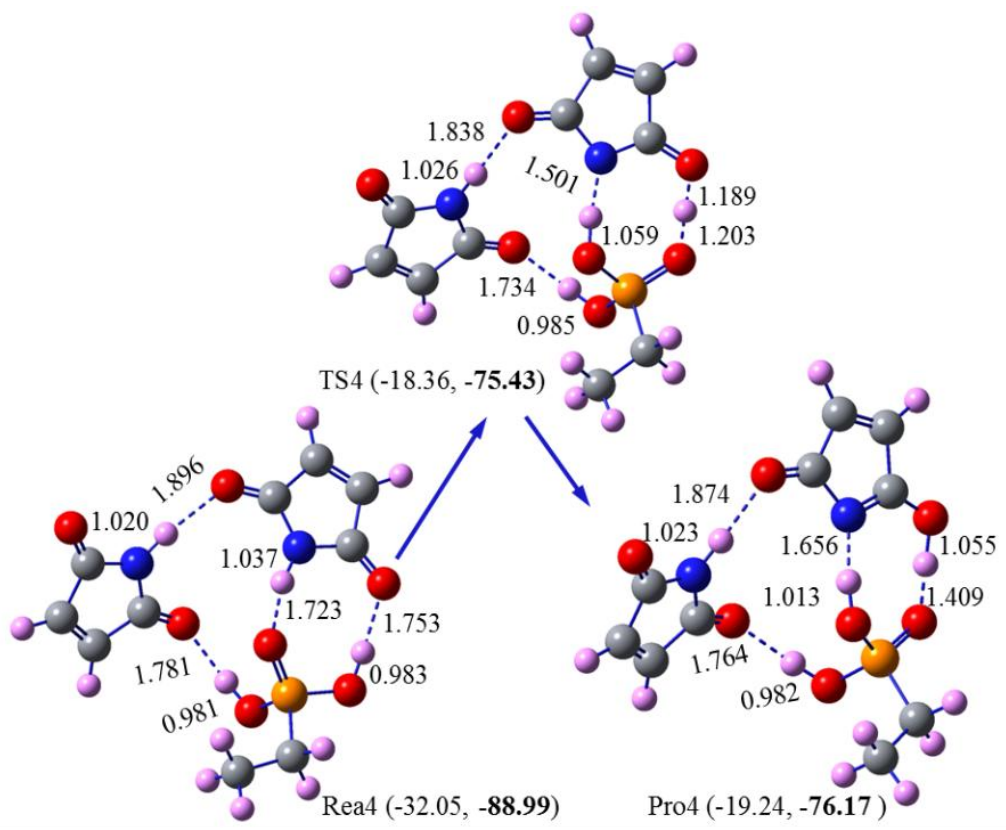

(b)

Fig. 4 Tautomerization of (a) MI mediated by EPA, (b) two MI molecules mediated by EPA, the unbolded numbers in parentheses are energies relative to the isolated molecules in gaseous phase and the bolded numbers are corresponding energies with solvation correction (color code: 
grey $\mathrm{C}$, red $\mathrm{O}$, cyan $\mathrm{N}$, purple $\mathrm{H}$, and yellow $\mathrm{P}$ ).

Figure 5 shows the overall conductivity of the MI-MPA composite at various compositions $\mathrm{MI}_{1-x} \mathrm{MPA}_{x}$ measured at $45{ }^{\circ} \mathrm{C}$ and $40 \% \mathrm{RH}$. Notice that the measurement for the pure MPA slab fails as MPA is sensitive to moisture and easily deliquescence, and the overall conductivity of the pure MI slabs at $40 \% \mathrm{RH}$ is below detecting limit. The overall characteristics of conductivity is comparable with that of the phosphonic acid and triazolyl functionalized polystyrene, where synergetic proton conduction is observed attributing to the interaction between the phosphonic acid group and the 1,2,3-triazolyl group. ${ }^{13}$ Though pure MPA possesses low conductivity, its conductivity greatly increases as more and more MI is composited into MPA. In MI-MPA composite composing of 0.663 MPA (MPA : MI $\approx 2: 1$ ), a maximum overall conductivity is observed at $1.87 \mathrm{mS} \mathrm{cm}{ }^{-1}$ also comparable to that of the phosphonic acid and triazolyl functionalized polystyrene. ${ }^{13}$ As more MI is composited, the overall conductivity decreases. Therefore, it is concluded that the MI can be applied as additive to improve the conductivity of phosphonic acid based proton conducting materials, and MI can be used as novel building block for the design of proton conducting materials. 


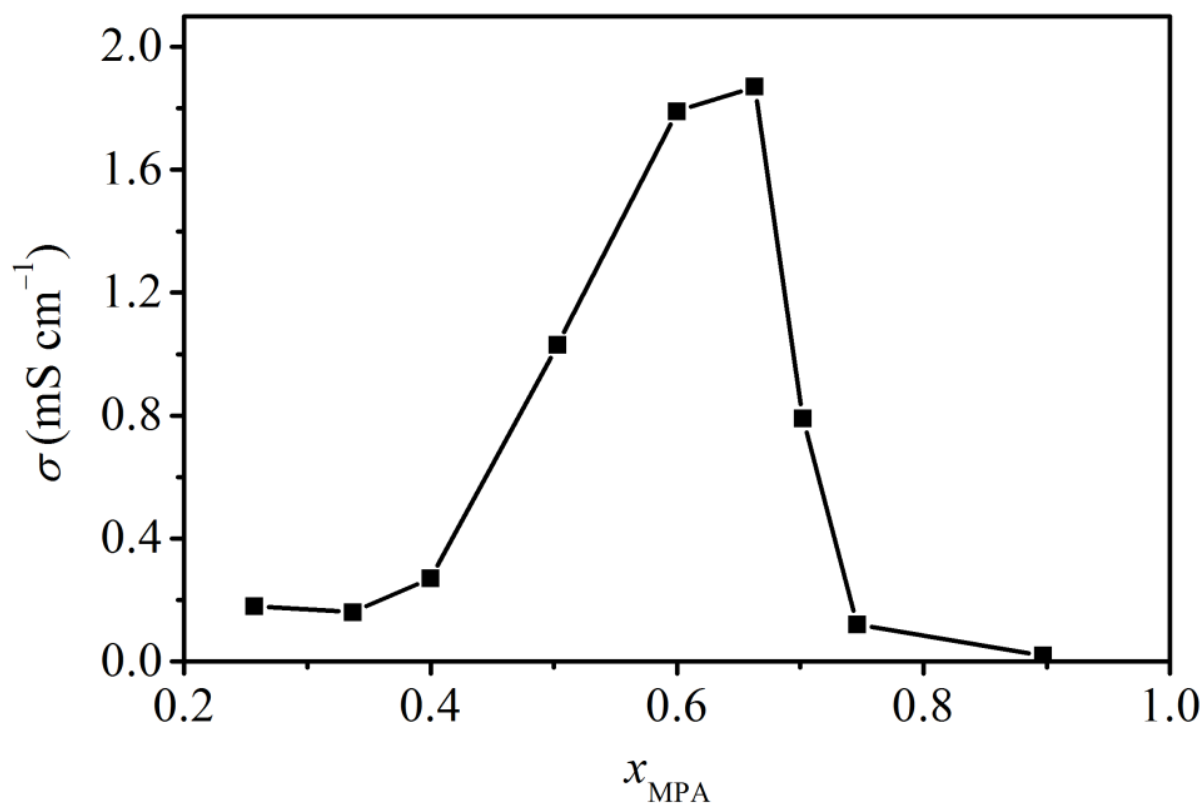

Fig. 5 Overall conductivity of the MI-MPA composite measured at $45{ }^{\circ} \mathrm{C}$ and $40 \%$ RH (The connecting lines are guide to the eyes.)

\subsection{Water and EPA mediated proton transfer between the MI homologues}

In previous sections, we discussed the possibility of MI as candidate building block for proton exchange membranes. In this section, we are going to evaluate the characteristics of two of its homologues of MI, including SI and PI. Figures 6 and 7 show the proton transfer pathways between two SI molecules and two PI molecules mediated by water and EPA, respectively. The energetics related to the proton transfer in SI and PI are summarized in table 5.

\subsubsection{Water and EPA mediated proton transfer between two SI molecules}

Differing from MI and PI, where we cannot localize any transition states for direct tautomerization without mediation molecules, we localize a transition state for direct tautomerization between two SI molecules without any mediation molecules as shown in figure 
6a. During direct tautomerization of two SI molecules, the $\mathrm{N}-\mathrm{H}$ distance increases from 1.027 (Rea5) to 1.410 (TS5), and finally to $1.572 \AA$ (Pro5), meanwhile, the O-H distance decreases from 1.851 , to 1.107 , and to $1.038 \AA$. In addition, tautomerization could also be mediated by water molecules and EPA molecules as shown in figures 6b-6e. From the typical energetics (table 5), the activation energy without any mediation molecules is $21.55 \mathrm{kcal} \cdot \mathrm{mol}^{-1}$, and this energy increases to 26.86 and $28.39 \mathrm{kcal} \cdot \mathrm{mol}^{-1}$ if the tautomerization is mediated by one or two water molecules with correction of PCM solvation model of water. These values are comparable with activation energies for intramolecular tautomerization of SI. For example, the activation energies for intramolecular keto-enol tautomerization of SI are 19.12 and 16.11 $\mathrm{kcal} \cdot \mathrm{mol}^{-1}$ with one and two water molecules, respectively, evaluated at theory level of MP2/6-311++G(d,p). ${ }^{39}$ In addition, the activation energies for water assisted enol-keto tautomerization of $N$-methylacetamide are also reported to be at slightly above $20.0 \mathrm{kcal} \cdot \mathrm{mol}^{-1} .40$

In our previous study, it was found that the phosphonic acid could greatly accelerate the tautomerization of 1,2,3-triazole by reduction of activation energy from about $1.0 \mathrm{eV}$ to about $0.35 \mathrm{eV}^{22}$ In this study, it is found that the activation energy of SI mediated by EPA molecule decreases to $11.26 \mathrm{kcal} \cdot \mathrm{mol}^{-1}$ with correction of PCM solvation model of phosphoric acid, consistent with MI and 1,2,3-triazole. 


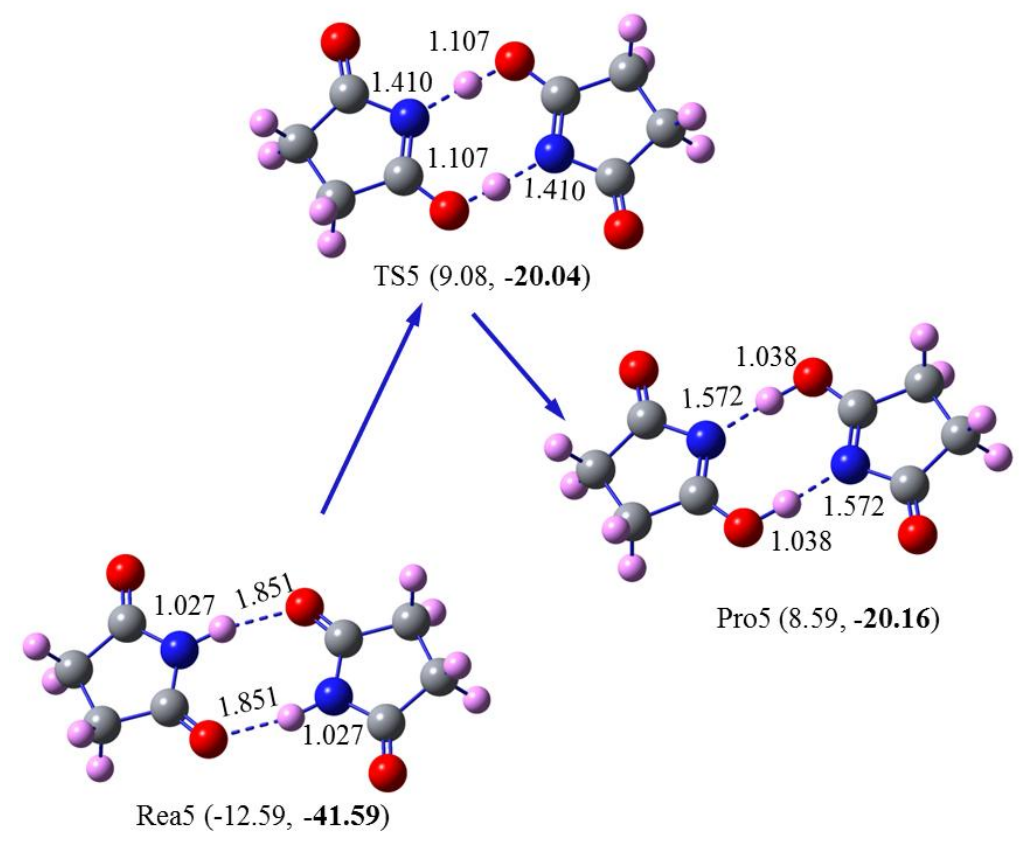

(a)
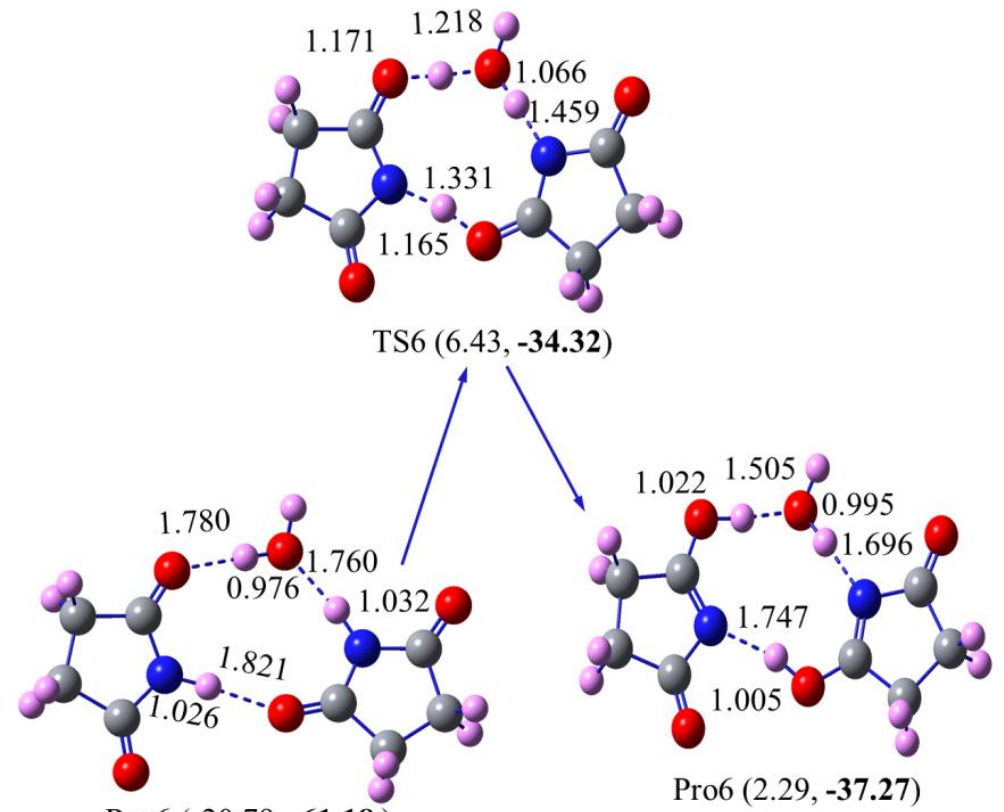

Rea6 (-20.79, -61.18)

(b) 


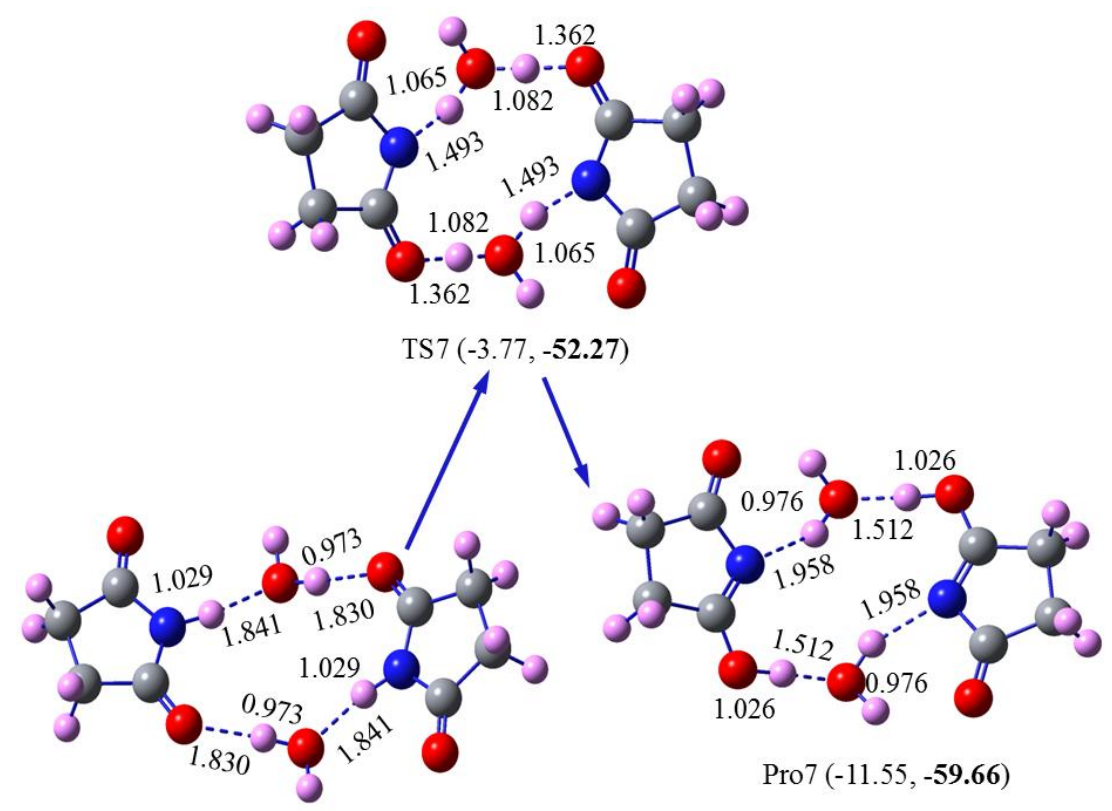

Rea7 (-30.63, -80.65)

(c)
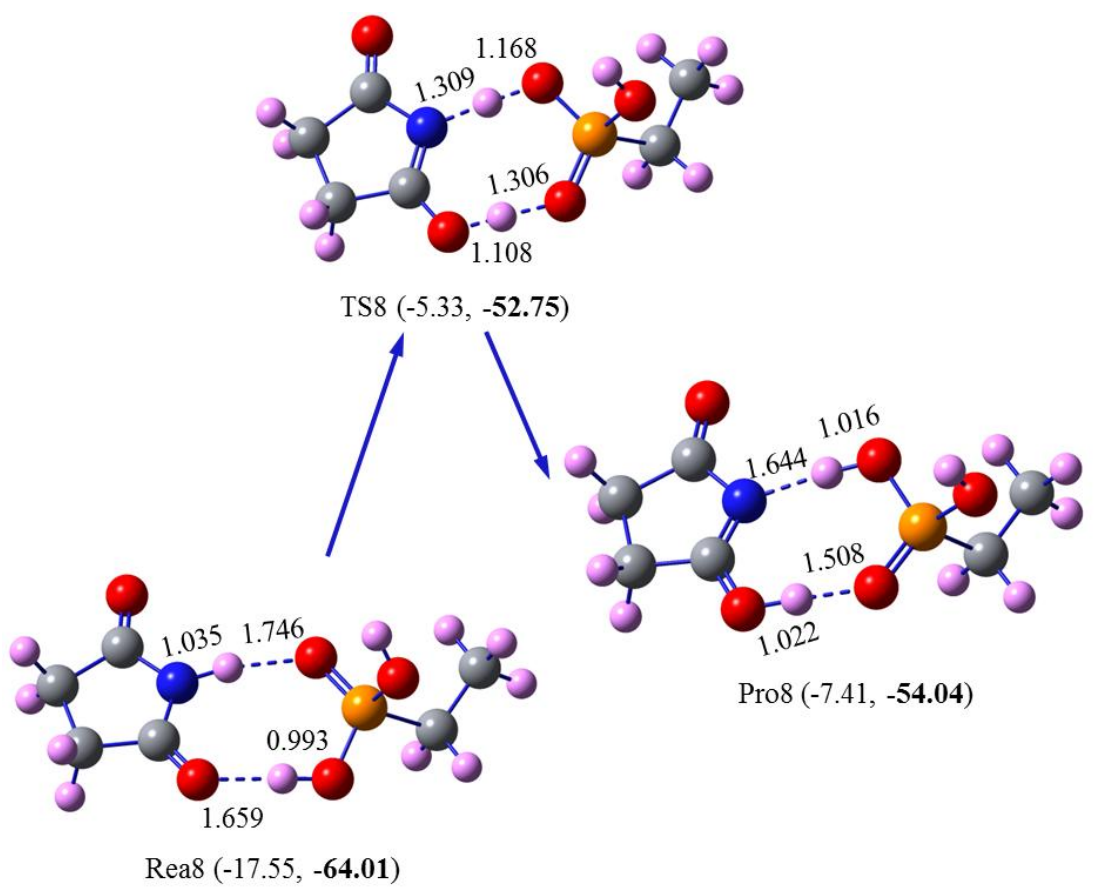

(d) 

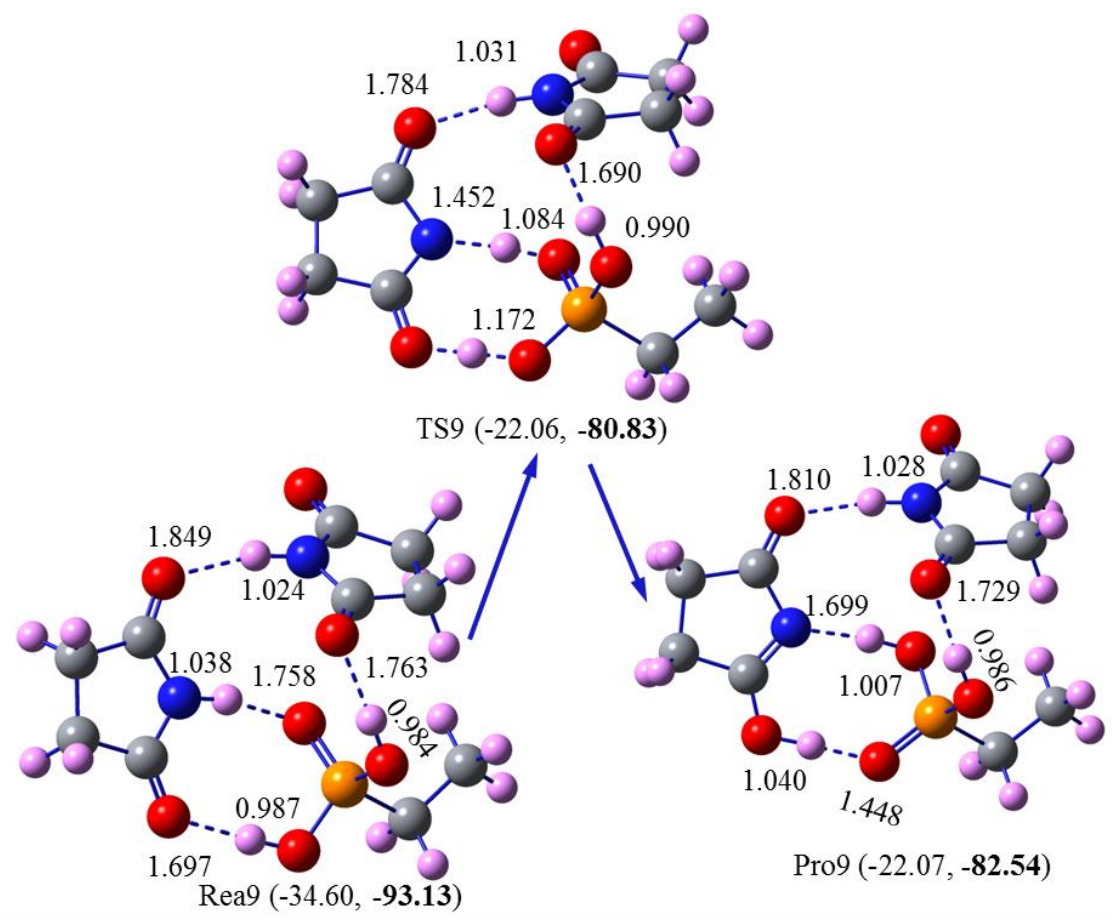

(e)

Fig. 6 Tautomerization of (a) two SI molecules, two SI molecules mediated by (b) one, and (c) two water molecules, (d) one SI, and (e) two SI molecules mediated by EPA, the unbolded numbers in parentheses are energies relative to the isolated molecules in gaseous phase and the bolded numbers are corresponding energies with solvation correction (color code: grey $\mathrm{C}$, red $\mathrm{O}$, cyan $\mathrm{N}$, and purple $\mathrm{H}$ ).

\subsubsection{Water and EPA mediated proton transfer between two PI molecules}

Figure 7 summarizes the proton transfer pathways between two PI molecules with the mediation of water molecules or EPA molecules. The structural parameters, the $\mathrm{N}-\mathrm{H}$ and $\mathrm{O} \cdots \mathrm{H}$ distances, are similar to those of the MI systems. The activation energies also show similar values and tendency compared with those of MI systems, and are lower than that of $\mathrm{PBI}-x \mathrm{H}_{3} \mathrm{PO}_{4}$ system $\left(17.2 \sim 20.2 \mathrm{kcal} \cdot \mathrm{mol}^{-1}\right) .{ }^{41}$ From table 5, it is obvious that activation energies for the 
keto to enol tautomerization are higher than that for the backward enol to keto activation, in consistent with literature. ${ }^{42}$
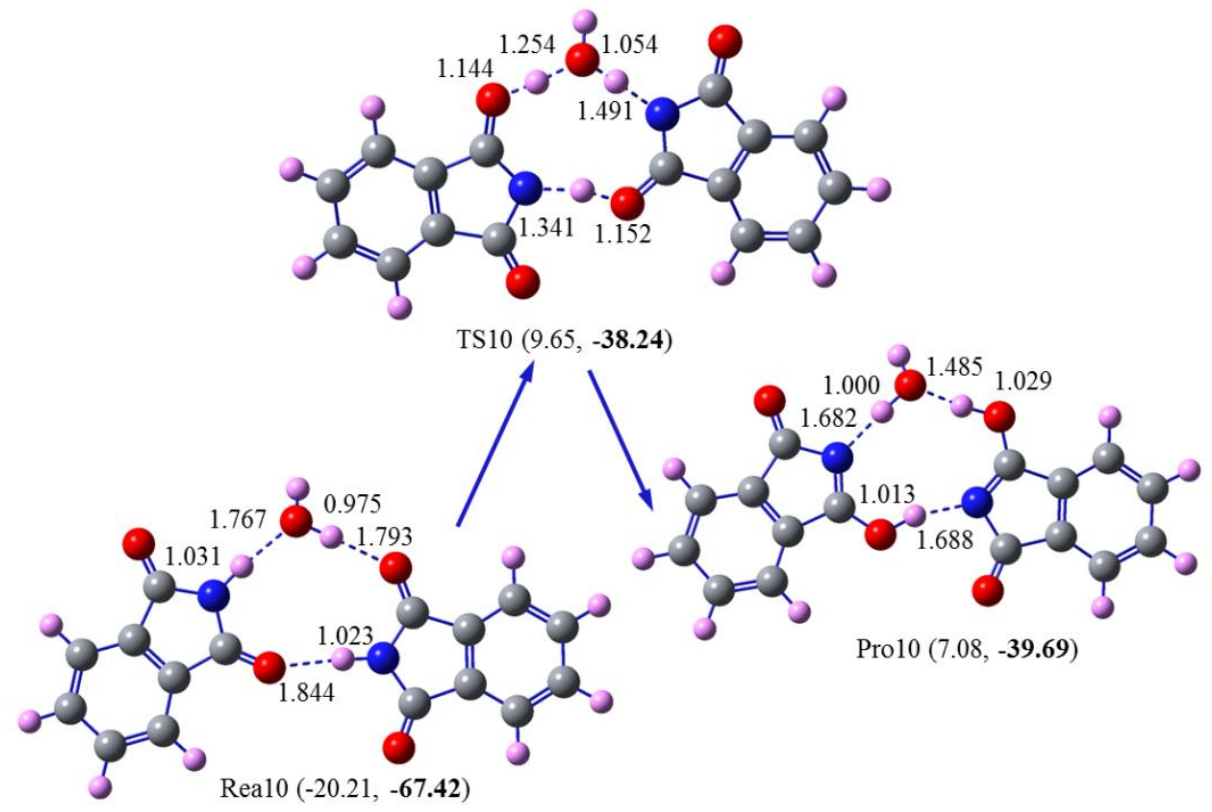

(a)
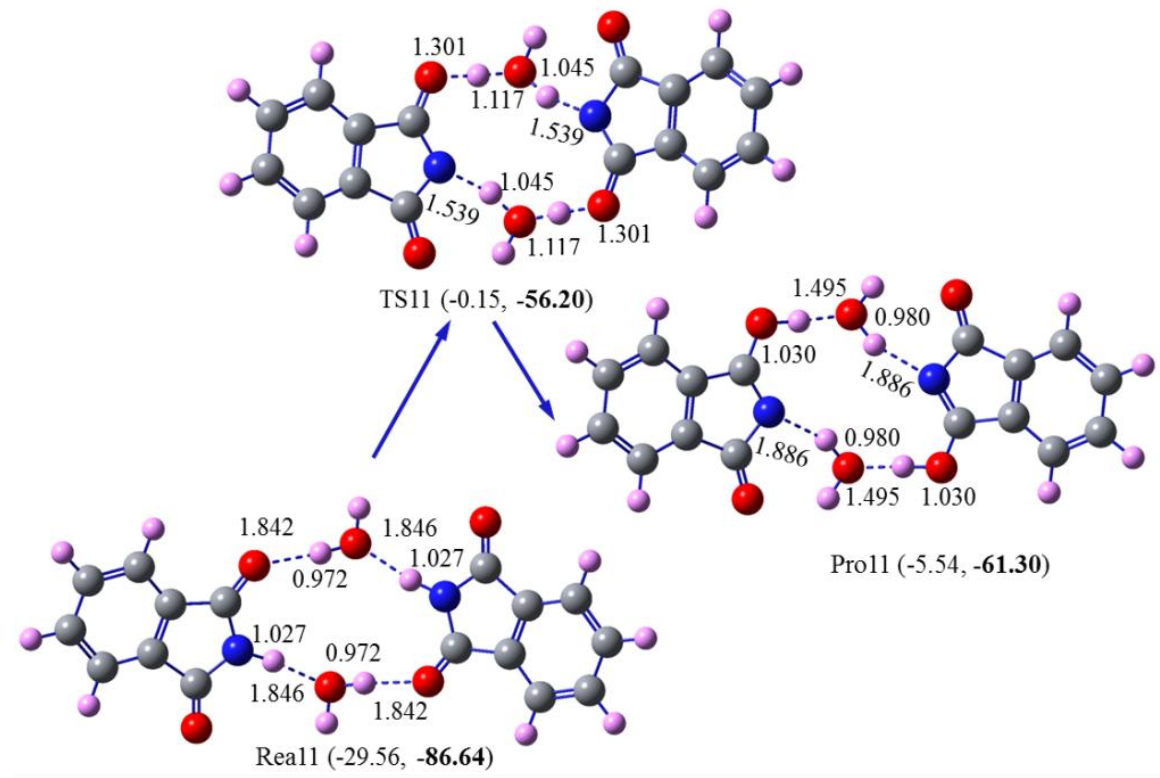

(b) 


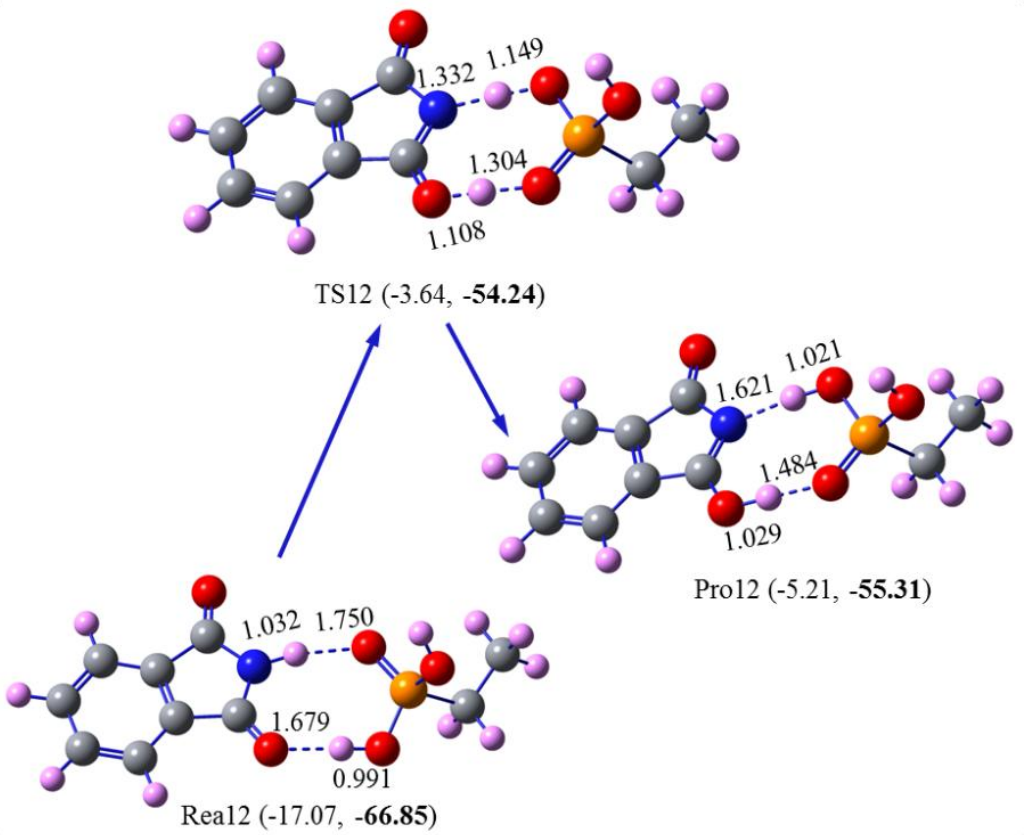

(c)

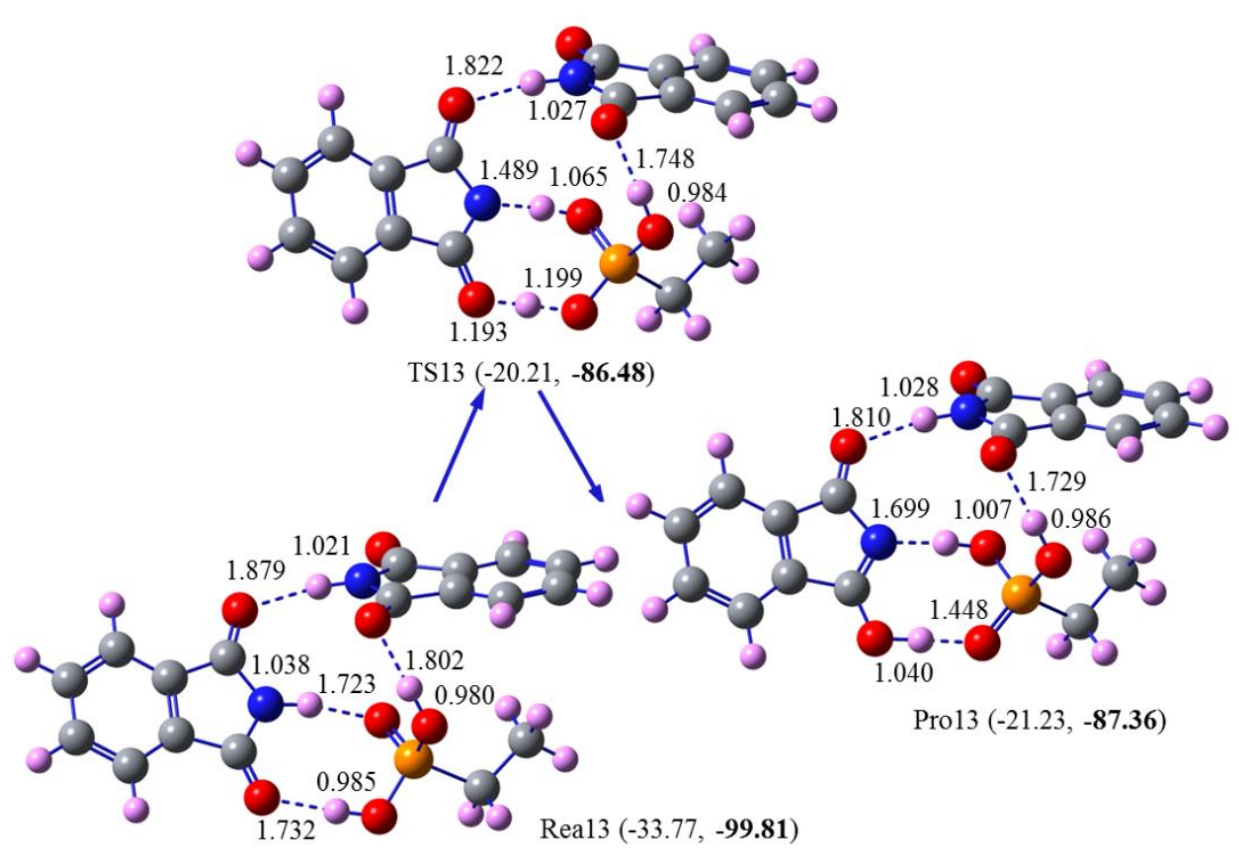

(d)

Fig. 7 Tautomerization of two PI molecules mediated by (a) one, and (b) two water molecules, and (c) one PI, and (d) two PI molecules mediated by EPA, the unbolded numbers in parentheses are energies relative to the isolated molecules in gaseous phase and the bolded numbers are 
corresponding energies with solvation correction (color code: grey $\mathrm{C}$, red $\mathrm{O}$, cyan $\mathrm{N}$, and purple H).

Table 5 BSSE corrected energetics $\left(\mathrm{kcal} \cdot \mathrm{mol}^{-1}\right)$ related to the proton transfer in SI and PI systems and the values in parentheses are energetics with PCM solvation correction

\begin{tabular}{|c|c|c|c|c|c|}
\hline & Rea & $\mathrm{TS}$ & Pro & $\Delta E_{a}^{\dagger}$ & $\Delta E_{a}{ }^{j}$ \\
\hline \multirow[b]{2}{*}{$\mathrm{SI}_{2}$} & -12.59 & 9.08 & 8.59 & 21.67 & 0.49 \\
\hline & $(-41.59)$ & $(-20.04)$ & $(-20.16)$ & $(21.55)$ & $(0.12)$ \\
\hline \multirow{2}{*}{$\mathrm{SI}_{2}-\mathrm{H}_{2} \mathrm{O}$} & -20.79 & 6.43 & 2.29 & 27.22 & 4.14 \\
\hline & $(-61.18)$ & $(-34.32)$ & $(-37.27)$ & $(26.86)$ & $(2.95)$ \\
\hline \multirow{2}{*}{$\mathrm{SI}_{2}-2 \mathrm{H}_{2} \mathrm{O}$} & -30.63 & -3.77 & -11.55 & 29.05 & 7.78 \\
\hline & $(-80.65)$ & $(-52.27)$ & $(-59.66)$ & (28.39) & $(7.39)$ \\
\hline \multirow{2}{*}{ SI-EPA } & -17.55 & -5.33 & -7.41 & 12.21 & 2.08 \\
\hline & $(-64.01)$ & $(-52.75)$ & $(-54.04)$ & (11.26) & $(1.30)$ \\
\hline \multirow[b]{2}{*}{$\mathrm{SI}_{2}-\mathrm{EPA}$} & -34.60 & -22.06 & -22.07 & 12.53 & 0.01 \\
\hline & $(-93.13)$ & $(-80.83)$ & $(-82.54)$ & $(12.30)$ & $(1.71)$ \\
\hline \multirow{2}{*}{$\mathrm{PI}_{2}-\mathrm{H}_{2} \mathrm{O}$} & -20.21 & 9.65 & 7.08 & 29.87 & 2.57 \\
\hline & $(-67.42)$ & $(-38.24)$ & $(-39.69)$ & $(29.18)$ & $(1.44)$ \\
\hline \multirow{2}{*}{$\mathrm{PI}_{2}-2 \mathrm{H}_{2} \mathrm{O}$} & -29.56 & 0.15 & -5.54 & 29.71 & 5.69 \\
\hline & $(-86.64)$ & $(-56.20)$ & $(-61.30)$ & $(30.44)$ & $(5.10)$ \\
\hline \multirow{2}{*}{ PI-EPA } & -17.07 & -3.64 & -5.21 & 13.43 & 1.57 \\
\hline & $(-66.85)$ & $(-54.24)$ & $(-55.31)$ & $(12.61)$ & (1.07) \\
\hline $\mathrm{PI}_{2}-\mathrm{EPA}$ & -33.77 & -20.21 & -21.23 & 13.55 & 1.02 \\
\hline
\end{tabular}




\footnotetext{
${ }^{\dagger}$ activation energy for keto to enol tautomerization $\$$ activation energy for enol to keto tautomerization
}

\section{Conclusions}

DFT calculations are applied to the investigation of H-bonding characteristics in MI, SI, and PI in terms transition states at theory level of $\omega B 97 X-D / 6-311+G(2 d, p)$. The intermolecular H-bonding energies are evaluated at $11.79,12.59$, and $12.10 \mathrm{kcal} \cdot \mathrm{mol}^{-1}$ for the MI, SI, and PI dimers with BSSE correction, respectively, indicating their similarity in H-bonding as the maximum difference in $\mathrm{H}$-bonding energy is only $0.29 \mathrm{kcal} \cdot \mathrm{mol}^{-1}$. The proton transfer barrier between two MI molecules mediated by water molecules is about $30.60 \mathrm{kcal} \cdot \mathrm{mol}^{-1}$ calculated in terms of transition state, and can be lowered further to about $13.22 \mathrm{kcal} \cdot \mathrm{mol}^{-1}$ mediated by EPA molecules (with PCM solvation model correction). From these calculations, it is concluded that proton transfer between MI molecules are efficient and can be improved by EPA mediation molecules. In addition, the homologues of MI, SI and PI, possess similar characteristics in H-bonding and proton transfer compared with MI.

From these characteristics, it is concluded that MI and its homologues possess the essential properties for intermolecular proton transport, and therefore, we propose that the MI and its homologues are building block candidates for the design of proton conducting polymers.

\section{Acknowledgements}

This work is supported by NSAF (Grant No. U1630102) and the Chinese National Science Foundation (Grant Nos. 21376147 and 21573143). The authors also acknowledge the High 
Performance Computing Center and the Laboratory for Microstructures, Shanghai University, for computing and structural characterization support.

\section{References}

1. Chandan, A., Hattenberger, M., El-Kharouf, A., Du, S. F., Dhir, A., Self, V., Pollet, B. G., Ingram, A., Bujalski, W., High temperature (HT) polymer electrolyte membrane fuel cells (PEMFC) - A review. J. Power Sources 2013, 231, 264-278.

2. Bakangura, E., Wu, L., Ge, L., Yang, Z. J., Xu, T. W., Mixed matrix proton exchange membranes for fuel cells: State of the art and perspectives. Prog. Polym. Sci. 2016, 57, 103-152.

3. Jahnke, T., Futter, G., Latz, A., Malkow, T., Papakonstantinou, G., Tsotridis, G., Schott, P., Gerard, M., Quinaud, M., Quiroga, M., et al., Performance and degradation of proton exchange membrane fuel cells: State of the art in modeling from atomistic to system scale. J. Power Sources 2016, 304, 207-233.

4. Jiang, S. P., Functionalized mesoporous structured inorganic materials as high temperature proton exchange membranes for fuel cells. J. Mater. Chem. A 2014, 2(21), 7637-7655.

5. Porozhnyy, M., Huguet, P., Cretin, M., Safronova, E., Nikonenko, V., Mathematical modeling of transport properties of proton-exchange membranes containing immobilized nanoparticles. Int. J. Hydrogen Energy 2016, 41(34), 15605-15614.

6. Yue, Z. Y., Cai, Y. B., Xu, S. A., Phosphoric acid-doped organic-inorganic cross-linked sulfonated poly(imide-benzimidazole) for high temperature proton exchange membrane fuel cells. Int. J. Hydrogen Energy 2016, 41(24), 10421-10429. 
7. Sood, R., Donnadio, A., Giancola, S., Kreisz, A., Jones, D. J., Cavaliere, S., 1,2,3-triazole-functionalized polysulfone synthesis through microwave-assisted copper-catalyzed click chemistry: A highly proton conducting high temperature membrane. Acs. Appl. Mater. Inter. 2016, 8(26), 16897-16906.

8. Pan, J. F., Wu, B., Wu, L., He, Y. B., Miao, J. B., Ge, L., Xu, T. W., Proton exchange membrane from tetrazole-based poly (phthalazinone ether sulfone ketone) for high-temperature fuel cells. Int. J. Hydrogen Energy 2016, 41(28), 12337-12346.

9. Lee, S. I., Yoon, K. H., Song, M., Peng, H., Page, K. A., Soles, C. L., Yoon, D. Y., Structure and properties of polymer electrolyte membranes containing phosphonic acids for anhydrous fuel cells. Chem. Mater. 2011, 24(1), 115-122.

10. Kreuer, K. D., Paddison, S. J., Spohr, E., Schuster, M., Transport in proton conductors for fuel-cell applications: Simulations, elementary reactions, and phenomenology. Chem. Rev. 2004, 104(10), 4637-4678.

11. Han, S., Yue, B., Yan, L., Research progress in the development of high-temperature proton exchange membranes based on phosphonic acid group. Acta Phys. Chim. Sin. 2014, 30(1), 8-21.

12. Tamura, Y., Sheng, L., Nakazawa, S., Higashihara, T., Ueda, M., Polymer electrolyte membranes based on polystyrenes with phosphonic acid via long alkyl side chains. J. Polym. Sci. A Polym. Chem. 2012, 50(20), 4334-4340.

13. Zhang, Y. P., Yue, B. H., Han, S. Y., Yan, L. M., Synergetic proton conducting effect in acid-base composite of phosphonic acid functionalized polystyrene and triazolyl functionalized polystyrene. $R S C A d v . \mathbf{2 0 1 4}, 4(64), 33702-33712$. 
14. Zhang, X. M., Yue, B. H., Yan, L. M., Zeng, G. B., Tao, S., Improving the comprehensive performances of phosphonic acid functionalized poly(ether sulfone) by compositing with 1H-1,2,3-triazol-4-yl functionalized poly(ether sulfone). Int. J. Hydrogen Energy 2016, 41(8), $4740-4750$.

15. Abouzari-Lotf, E., Ghassemi, H., Mehdipour-Ataei, S., Shockravi, A., Phosphonated polyimides: Enhancement of proton conductivity at high temperatures and low humidity. $J$. Membr. Sci. 2016, 516, 74-82.

16. Zhou, Z., Liu, R., Wang, J. H., Li, S. W., Liu, M. L., Bredas, J. L., Intra- and intermolecular proton transfer in $1 H(2 H)-1,2,3$-triazole based systems. J. Phys. Chem. A 2006, 110(7), $2322-2324$.

17. Aslan, A., Bozkurt, A., Development and characterization of polymer electrolyte membranes based on ionical cross-linked poly(1-vinyl-1,2,4 triazole) and poly(vinylphosphonic acid). $J$. Power Sources 2009, 191(2), 442-447.

18. Subbaraman, R., Ghassemi, H., Zawodzinski, T., Triazole and triazole derivatives as proton transport facilitators in polymer electrolyte membrane fuel cells. Solid State Ionics 2009, 180(20), 1143-1150.

19. Kalia, S., Sharma, A., Kaith, B. S., Ab initio study of gas phase and water-assisted tautomerization of maleimide and formamide. J. Chem. Sci. 2007, 119(6), 617-624.

20. Li, X., Yan, L., Yue, B., Maleimide: a potential building block for the design of proton exchange membranes studied by ab initio molecular dynamics simulations. RSC Adv. 2015, 5(98), 80220-80227. 
21. Paddison, S. J., Kreuer, K. D., Maier, J., About the choice of the protogenic group in polymer electrolyte membranes: Ab initio modelling of sulfonic acid, phosphonic acid, and imidazole functionalized alkanes. Phys. Chem. Chem. Phys. 2006, 8(39), 4530-4542.

22. Yue, B. H., Yan, L. M., Han, S. Y., Xie, L. Q., Proton transport pathways in an acid-base complex consisting of a phosphonic acid group and a 1,2,3-triazolyl group. J. Phys. Chem. B 2013, 117(26), 7941-7949.

23. Zhou, Y., Yang, J., Su, H., Zeng, J., Jiang, S. P., Goddard, W. A., Insight into proton transfer in phosphotungstic acid functionalized mesoporous silica-based proton exchange membrane fuel cells. J. Am. Chem. Soc. 2014, 136(13), 4954-4964.

24. Zhang, D. F., Yan, L. M., Probing the acid-base equilibrium in acid-benzimidazole complexes by ${ }^{1} \mathrm{H}$ NMR spectra and density functional theory calculations. J. Phys. Chem. B 2010, 114(38), 12234-12241.

25. Xie, L. Q., Liu, H. T., Han, S. Y., Yue, B. H., Yan, L. M., Hydrogen bond and proton transport in acid-base complexes and amphoteric molecules by density functional theory calculations and ${ }^{1} \mathrm{H}$ and ${ }^{31} \mathrm{P}$ nuclear magnetic resonance spectroscopy. J. Phys. Chem. B 2013, 117(50), 16345-16355.

26. Goerigk, L., Grimme, S., A thorough benchmark of density functional methods for general main group thermochemistry, kinetics, and noncovalent interactions. Phys. Chem. Chem. Phys. 2011, 13(14), 6670-6688.

27. Cohen, A. J., Mori-Sánchez, P., Yang, W., Challenges for density functional theory. Chem. Rev. 2011, 112(1), 289-320. 
28. Burke, K., Perspective on density functional theory. J. Chem. Phys. 2012, 136(15), 0901.

29. Zhao, Y., Truhlar, D. G., Density functional theory for reaction energies: Test of meta and hybrid meta functionals, range-separated functionals, and other high-performance functionals. $J$. Chem. Theory Comput. 2011, 7(3), 669-676.

30. Chai, J. D., Head-Gordon, M., Long-range corrected hybrid density functionals with damped atom-atom dispersion corrections. Phys. Chem. Chem. Phys. 2008, 10(44), 6615-6620.

31. Schwabe, T., Grimme, S., Double-hybrid density functionals with long-range dispersion corrections: Higher accuracy and extended applicability. Phys. Chem. Chem. Phys. 2007, 9(26), 3397-3406.

32. Christensen J. H., Smith A. J., Reed R. B., L., E. K., Dielectric properties of phosphoric acid solutions at $25^{\circ}$ C. J. Chem. Eng. Data 1966, 11(1), 60-63.

33. Frisch, M. J., Trucks, G. W., Schlegel, H. B., Scuseria, G. E., Robb, M. A., Cheeseman, J. R., Scalmani, G., Barone, V., Mennucci, B., Petersson, G. A., et al., Gaussian 09, revision D.01; Gaussian, Inc.: Wallingford, CT, 2009.

34. Cox, P. J., Parker, S. F., Maleimide. Acta Crystallogr. Sect. C: Cryst. Struct. Commun. 1996, $52,2578-2580$.

35. Li, Q., Aili, D., Savinell, R. F., Jensen, J. O. ed.; Acid-Base Chemistry and Proton Conductivity. In High Temperature Polymer Electrolyte Membrane Fuel Cells, Springer: 2016; pp 37-57.

36. Dean, J. A. ed. Lange's handbook of chemistry (15 ${ }^{\text {th }}$ ed.). McGraw-Hill Professional, New York, United States: 1998. 
37. Li, W., Shen, C., Gao, S., Yin, S., Li, H., Preparation and characterization of phosphonic acid functionalized siloxane/polyimide composite proton exchange membranes. Solid State Ionics 2016, 287, 1-7.

38. Yue, Z., Cai, Y.-B., Xu, S., Phosphoric acid-doped cross-linked sulfonated poly(imide-benzimidazole) for proton exchange membrane fuel cell applications. J. Membr. Sci. 2016, 501, 220-227.

39. Valadbeigi, Y., Farrokhpour, H., Simple and water-assisted tautomerism in succinimide. Struct. Chem. 2015, 26(2), 539-545.

40. Li, Q., Xue, Y., Yan, G., Water-assisted enol-to-keto tautomerism of a simple peptide model: A computational investigation. J. Mol. Struc.-THEOCHEM 2008, 868(1-3), 55-64.

41. Pu, H., Meyer, W. H., Wegner, G., Proton transport in polybenzimidazole blended with $\mathrm{H}_{3} \mathrm{PO}_{4}$ or $\mathrm{H}_{2} \mathrm{SO}_{4}$. J. Polym. Sci. Pol. Phys. 2002, 40(7), 663-669.

42. Pérez, P., Contreras, R., A theoretical analysis of the gas-phase protonation of hydroxylamine, methyl-derivatives and aliphatic amino acids. Chem. Phys. Lett. 1998, 293(3), 239-244. 